\title{
What happiness science can learn from John Stuart Mill
}

\author{
Willem van der Deij1
}

\begin{abstract}
Many researchers studying subjective wellbeing (SWB) understand SWB as a concept that is close to Bentham's notion of happiness. This conception of happiness is philosophically controversial, because it treats pleasure as a homogenous experience. I analyze an important deviation from Bentham in John Stuart Mill's Utilitarianism and its relevance for SWB research: qualitative differences in pleasurable experiences. I argue that in cases where lives involving qualitatively different experiences are compared, Mill's qualitative perspective is incompatible with an important assumption in the SWB literature: that happiness can be meaningfully rated by people on a scale. I illustrate the problem by means of the question of whether becoming a parent makes people happier. I analyze whether the problem can be avoided on alternative views of happiness, but argue that on all plausible accounts of happiness, the problem persists. I conclude that the problem it poses for self-reported happiness is genuine and should be acknowledged by SWB researchers. I end by discussing the ways in which this conclusion can help the study of happiness move forward.
\end{abstract}

Keywords: happiness, measurement, pleasure, John Stuart Mill, Jeremy Bentham, subjective wellbeing

It is better to be a human being dissatisfied than a pig satisfied; better to be Socrates dissatisfied than a fool satisfied. And if the fool, or the pig, are of a different opinion, it is because they only know their own side of the question. The other party to the comparison knows both sides.

- John Stuart Mill, Utilitarianism

\section{Introduction: Happiness and subjective wellbeing}

"Taking all things together, how happy would you say you are?" (European social survey). If you answer this question - on a scale from 0-10 - with a high number, and you answer it faithfully, is your life going well for you? This question, and variations thereof, is the key measurement instrument defining the concept of subjective wellbeing (SWB) - a popular approach to the measurement of wellbeing in the social sciences. Not every SWB researcher would answer the question with a clear "yes," but many believe that SWB can capture happiness, and that happiness is, in the very least, an important part of wellbeing (e.g. Kesebir \& Diener, 2008) ${ }^{1}$. Many researchers seem to understand SWB as a concept that is close to Bentham's notion of happiness (see Fleurbaey \& Blanchet, 2013). In fact, explicit references to Bentham's philosophy are not at all rare in the SWB literature (e.g. Kahneman, Wakker, \& Sarin, 1997; Kahneman et al., 2004; Veenhoven, 2010; Dolan \& Metcalfe, 2012). The particular conception of happiness that social scientists use is closely connected with the question of how

${ }^{1}$ By “wellbeing" I mean prudential value: how well a life is going for the person whose life it is (Sumner 1996, 20). 
- if at all - happiness can be measured. On Bentham's hedonistic perspective, measuring happiness by means of asking people about their experiences seems a straightforward methodology.

Bentham understands happiness as a unidimensional quality of experience. On this view, it seems plausible that people are able to recognize and evaluate their own happiness. Nevertheless, Bentham's hedonism is quite controversial in philosophy for its treatment of pleasure (e.g. Nussbaum, 2004; cf. Tännsjö, 2007). Much criticism of the SWB approach about the measurement of happiness or wellbeing seems to have focused on the unsatisfactory features of the hedonist conception of happiness underlying the approach in one way or another (O'Neill, 2006; Nussbaum, 2008; Sen, 2008; Raibley, 2012; Fleurbaey \& Blanchet, 2013; Stewart, 2014; Crespo \& Mesurado, 2014). In a critical essay of the hedonistic foundation of positive psychology, Martha Nussbaum writes: "Modern psychology follows Bentham. Indeed, Kahneman explicitly traces his own conception of 'hedonic flow' to Bentham (see, for example, Kahneman and Krueger 2006, p. 4). And yet, is Bentham correct?" (2008, S82). Nussbaum certainly believes that Bentham was not, and represents many fellow philosophers in this.

One way in which hedonism can be made more acceptable to those who oppose the view is by moving towards a qualified version of hedonism, such as John Stuart Mill's view on happiness (Mill, 1871; see e.g. Sen, 2006; Nussbaum 2008). Mill retained Bentham's view that happiness is constituted by pleasure, but departed from Bentham by suggesting that pleasures - that is, pleasurable experiences ${ }^{2}$ - do not only differ in terms of duration and intensity ${ }^{3}$, but also differ qualitatively. Because Mill's view on happiness seems more plausible to critics by virtue of its more nuanced treatment of pleasure, his view on happiness is sometimes proposed as a more attractive alternative (e.g. Nussbaum, 2008). By virtue of its more nuanced treatment of pleasure, Mill's account seems to provide a more attractive and plausible basis to serve as a foundation for the study of happiness. However, Mill's view also makes happiness more difficult to measure. As I will argue, there is a perspective in Mill's view on happiness that problematizes the orthodoxy within the SWB literature to use self-reports as measures of happiness, particularly in cases where qualitatively different lives are compared. In this essay, I will analyze this perspective and its relevance for SWB research. I illustrate the problem Mill's perspective poses with the example of SWB research on the happiness of parents compared to the childless. I argue that the perspective does not rely on a metaphysically demanding interpretation of Mill's qualitative hedonism, but is based on a simple and plausible assumption about the quality of experience. While on some conceptions of happiness it may seem plausible that people have the ability to evaluate their happiness independently of the kind of experiences they have already had, I argue that Mill's rejection of this idea is convincing and compatible with a variety of views on happiness. Hence, it raises serious doubts that SWB can capture happiness in a satisfactory fashion, particularly in cases where lives with qualitatively different experiences are compared.

Sections 2 and 3 are preliminaries. In section 2, a necessary condition for measuring happiness by means of self-reported SWB measures is discussed, and in section 3, Mill's qualitative perspective on pleasure is presented. Section 4 presents the main argument: Mill's qualitative perspective on happiness is plausible, but creates doubt it can be measured by selfreports. Section 5 discusses the example of SWB research on the effect of parenting on happiness. Objections and the relevance of Mill's perspective for alternative views on the

2 I follow Schmidt-Petri (2006) here in making a distinction between "a pleasure" and "pleasure" in Mill.

3 To Bentham, pleasures - meaning pleasurable experiences - also differ in other categories that seem to be less central here: certainty, propinquity, fecundity, purity and extent. 
nature of happiness are discussed in sections 6 and 7 respectively. In section 8, I discuss the relationship between this argument and another objection to SWB: the adaptation problem. Section 9 concludes and discusses implications for future happiness research.

\section{Measuring SWB}

There is a large variety of SWB research. Nevertheless, we can say that SWB roughly comes in two types of constructs, which are sometimes considered to be similar in meaning, and sometimes considered to be different views on what SWB should capture: life satisfaction and happiness (e.g. Veenhoven, 2010; Hansen, 2012). On the Benthamite view, SWB captures pleasurable - or enjoyable ${ }^{4}$ experiences in life, and many SWB researchers would see an evaluation of enjoyable experiences in life to be a very similar exercise to evaluating satisfaction with life ${ }^{5}$ (e.g. MacKerron, 2012). However, some researchers do take life satisfaction to be an altogether different conception of happiness (see Haybron, 2007b for a discussion), and thereby deviate from the Benthamite underpinnings I have thus far described. It is also common to understand life satisfaction as a whole different concept from happiness altogether. For the purposes of simplicity, I will focus my attention on SWB research that aims to capture a hedonistic notion of happiness. However, in section 6 I will address some of the implications of the argument for research aimed at capturing life satisfaction conceptions of happiness as well.

The study of subjective wellbeing is not necessarily committed to the view that subjective wellbeing is a sufficiently good measure of wellbeing simpliciter, though many authors are (see, Angner 2010). What the field of study is committed to is the view that subjective experiences, or attitudes towards life, can be meaningfully rated on a scale with a reasonably limited amount of error ${ }^{6}$ (e.g. Ferrer-i-Carbonell, 2002). This does not imply that someone with a higher self-reported happiness rating is necessarily happier than someone with a lower rating (see Angner, 2013); people may be imperfect in their judgment. People may make mistakes. However, in order for SWB to capture happiness, it is required that these errors occur randomly - in other words, that they are not structural. The precise formulation of this requirement may depend on the kind of comparison of SWB that is made. But consider, for example, that we want to compare two different groups. A significant share of one group may be overly-optimistic about their subjective wellbeing, such that two equally happy people would rate their happiness differently, due to such optimism. For example, if educated people tend to interpret a happiness scale differently than others, we may draw the wrong conclusions about the effect of education on happiness. In that case, SWB would be an unsatisfactory measure of happiness. More generally, in order to draw conclusions from self-reported SWB data on happiness, errors of this sort - reporting errors - need to be random. We can formulate this as follows:

Ratability: In order for a self-reported measure of subjective wellbeing to be meaningful, people need to be able to rate their subjective wellbeing - be it

\footnotetext{
${ }^{4}$ Bentham uses the word "pleasure," but modern formulations of hedonism often replace "pleasurable" by "enjoyable" (Crisp, 2006) to de-emphasize the connotation with bodily pleasures. I will use the two terms interchangeably throughout the article.

${ }^{5}$ Ruut Veenhoven, for instance, writes: "Satisfaction is also the subjective experience Jeremy

Bentham had in mind".

${ }^{6}$ George MacKerron, for instance, writes: "SWB data consist, more or less by definition, of the aggregated selfreports of individuals - what people say about themselves when asked" $(2012,708)$.
} 
happiness or life satisfaction - such that reporting errors do not occur structurally. In other words, different people - or, alternatively, people over time - may evaluate the same level of happiness differently, but these deviations should not have any relevant structural patterns.

\section{Mill and qualitative hedonism}

Hedonism is the view that happiness is constituted by the balance of pleasurable experience over painful experience. Hedonism as a theory of wellbeing additionally holds that wellbeing is constituted by happiness. This latter view is particularly controversial in philosophy ${ }^{7}$, but as a view about happiness, hedonism is quite popular (see Haybron, 2005). Bentham, as well as Mill, held both views of hedonism, but for the present purpose we will focus on hedonism as a view on the nature of happiness. While both hedonists, Mill's view deviates from Bentham with respect to the nature of pleasure. Bentham's view on happiness is characterized by the idea that pleasure is a homogenous sensation which is shared by all pleasurable experiences (Sumner, 1996; Nussbaum, 2004; 2008; Crisp, 2006). This feature is central to its appeal to happiness researchers. If pleasure is, indeed, a homogenous sensation, it seems plausible that it can be readily detected, and, consequently, rated by people. Moreover, the homogeneity of Bentham's view on pleasure seems to play an important role in its liberalism with respect to pleasure, such as illustrated in his well-known view that there is nothing particularly better about poetry compared to pushpin. Nevertheless, there are two problems with Bentham's account of happiness as constituted by homogenous sensation.

Firstly, Bentham's homogenous hedonism is vulnerable to the problem that there are certain experiences that we would call enjoyable that feel very different from typical enjoyable experiences - for example, enjoyment from masochism, or from running a marathon. But there are also less trivial examples, such as Fred Feldman's (2010) example of a woman who gives birth. While she is feeling ecstatic about holding her newborn in her arms, she is also in deep physical pain. What these examples show is that pleasure does not seem to share any specific phenomenological trait.

Another problem for a homogenous view of pleasure is that on that view, any pleasurable experience can be equated with a certain amount of another pleasurable experience to produce the same amount of pleasure. In other words, while someone who likes poetry may find it more enjoyable than pushpin, as long as she enjoys pushpin as well, at some point a large amount of pushpin will be more enjoyable than some amount of poetry. This can lead to deeply counterintuitive conclusions. One well-known counter-example illustrating this problem is the example of the long oyster life (Crisp, 2006). While an oyster may only experience some pleasure, a very long oyster life would have to be more pleasurable than a human life that lasts eighty years. If it is not, the life of the oyster can be extended, such that at some point, the pleasure enjoyed in the oyster's life must compensate for the more intense pleasure of a human life. Many find the conclusion that the very long life of an oyster is more enjoyable than a normal human life counter-intuitive.

\footnotetext{
7 The most widely discussed argument against this view is the experience machine objection, originally formulated by Robert Nozick (1974; cf. Kawall, 1999; Silverstein, 2000; Weijers, 2011; see Weijers \& Schouten, 2013 for a contemporary discussion). The argument is based on the following example: consider a machine which you could plug in that would create a virtual world for you in which you would have the most amazing experiences. Someone in this machine would have incredibly pleasurable experiences, and would be happy, but, Nozick argues, would not lead an enviable life.
} 
These problems for Bentham's account resonate in some of the criticism on the conceptual framework employed by SWB researchers. Nussbaum, for instance, writes: "The apparent fact that pleasures differ in quality, that the pleasure of steak eating is quite different from the pleasure of listening to Mahler's Tenth, bothered Bentham not at all; he does not discuss such examples" (2008, S83; see Crespo \& Mesurado, 2014 for similar worries).

Mill was aware of such criticisms of hedonism - in particular, by the problem that any pleasure can be compensated for by some amount of another pleasure - and addresses them in Utilitarianism. Mill believed that many classical hedonist theories were able to deal with such objections to some extent by arguing that mental pleasures were better than bodily pleasures in terms of "permanency, safety, uncostliness, etc." (Mill, 1871, 56). However, Mill believed that such solutions were not sufficiently able to distinguish higher and lower experiences, such as that of a human life, and that of an oyster. Mill argued that there is a difference in kind between some pleasures in life: "It would be absurd that while, in estimating all other things, quality is considered as well as quantity, the estimation of pleasures should be supposed to depend on quantity alone" (56). Intuitively, there is something very attractive about Mill's account of happiness. The experience of climbing Kilimanjaro does not only differ from a day of playing board games in the amount and intensity of pleasure involved, the experience also seems qualitatively different. In a recent defense, Roger Crisp (2006) argues that what all such different enjoyable experiences share is that they are enjoyable, but that apart from that, they may all feel different.

There are different interpretations of how Mill's view should be made more precise. While it is clear that Mill believed that some pleasures were qualitatively different from others, there is a variety of views on why that is. In particular, there is much debate about the question of whether Mill's qualitative hedonism implies that a pleasure of a certain quality is preferred to any amount of pleasures of a lower quality. In other words, are qualitatively different pleasures lexicographically ordered? In Utilitarianism, Mill attempts to clarify his meaning of qualitative difference by reference to competent judges:

"If one of two [pleasures] is, by those who are competently acquainted with both, placed so far above the other that they prefer it, even though knowing it to be attended with a greater amount of discontent, and would not resign it for any quantity of the other pleasure which their nature is capable of, we are justified in ascribing to the preferred enjoyment a superiority in quality, so far outweighing quantity as to render it, in comparison, of small account." $(1871,56)$

On the classical view of interpreting Mill - the lexicographical view - the passage is read as explaining a lexicographical difference between qualitatively different pleasures (Riley, 2003; see Booher, 2007). On this view, the pleasure experienced from higher pleasures can never be compensated by any amount of lower pleasures. This view is wedded to the idea that pleasurable experiences are intrinsically different from each other with respect to the pleasure they produce (Schmidt-Petri, 2006). On the lexicographical view, either higher pleasures feel infinitely better, or they simply are infinitely more pleasurable than lower pleasures for other reasons. Jonathan Riley (1999; 2003) defends the view. The view is controversial because it begs the question of what it is about pleasures that makes them qualitatively different. Surely some experiences feel different in kind, but why would we assume that some are of such a higher quality that they are lexicographically ordered with respect to pleasure? Reading poetry does not really seem to feel infinitely more pleasurable than pushpin. However, if poetry is infinitely better despite it not feeling infinitely better, the view seems to deviate from hedonism (Scarre, 1997). Riley (1999) argues that some experiences do indeed feel infinitely more pleasurable than 
others. While such a defense is internally consistent, it relies heavily on the existence of an infinite difference of pleasure in felt experiences, a view that is highly contestable.

A second reading - the epistemological view - is provided by Christoph Schmidt-Petri (2003; 2006; but also Booher, 2007; Crisp, 2006; see also Saunders, 2011 for a discussion). In his view, Mill's qualitatively different pleasures need not imply that the higher pleasures are preferred to any amount of lower pleasures. A higher pleasure is definitely a lot more pleasurable than a lower one, but that does not mean that their difference in pleasure needs to be considered lexicographic. In Schmidt-Petri's account, Mill's passage suggests that if competent judges prefer one pleasure over an infinite amount of another pleasure, they are justified in ascribing a difference in quality between the pleasurable experiences, but it need not imply that any qualitative difference means that the experiences are infinitely more - or less pleasurable. Schmidt-Petri understands Mill's passage as making an epistemological point: people who have not experienced higher pleasures are not able to appreciate them and compare them to lower pleasures. Some enjoyable experiences last equally long, and are equally intense as other experiences, but nevertheless produce more pleasure. The only way to learn whether this is the case is to experience both and judge.

In short, while there are two radically different interpretations of Mill's views on qualitative differences in pleasure, both views consider a person who has not experienced a certain pleasure to be in a disadvantaged position to evaluate it. We can call this the qualitative view of pleasure, or more generally, the Qualitative View of Experiences (QVE).

QVE: There are differences in the quality of experiences, and the variety of qualities of experience we have had influences the way we evaluate them. Two experiences that are of a different quality can only be fully evaluated by someone who has experienced both ${ }^{8}$.

A person who has not fully experienced higher pleasures may believe her life is happy. But, as the addendum to Mill's famous passage cited in the epigraph illustrates: Mill believes that a person who has only experienced lower pleasures is in a bad position to make a comparison of happiness between the higher and lower pleasures. For Mill, this has an important implication for people's own perceptions of their happiness, or for the importance of their sense of satisfaction. Mill argues: “Whoever supposes that ... the superior being, in anything like equal circumstances, is not happier than the inferior, confounds the two very different ideas, of happiness, and content" (57). A person can be content, feel satisfied, and believe herself to be happy, but when this is based on having pleasurable experiences of a low quality, her happiness may not weigh up against the higher quality experiences of a person who does not feel quite as satisfied, and does not believe herself to be happy.

Mill's language may be archaic and elitist. But consider the example of someone who has never been in a committed relationship. She may believe it to be dull and restrictive, and be perfectly satisfied with the situation as it is. Mill's perspective indicates that it may happen that - if being in a committed relationship is a higher pleasure for her - after being in such a relationship, she learns that it is much more enjoyable than not being in one. She may, after learning this, be equally satisfied, or even less satisfied, but this need not imply that it is less

\footnotetext{
8 This need not imply that people cannot make justified guesses about other people's happiness. We may be justified in judging people in deprived circumstances to be unhappy, without having experienced it. Our imaginative powers are likely to be roughly reliable, especially if it comes to obvious misery. However, the QVE implies that when we experience something new, it changes how we evaluate our own happiness.
} 
enjoyable. According to Mill's perspective that I want to defend here, such experiences can alter the way we evaluate our own happiness.

\section{Mill's qualitative perspective and SWB}

QVE, if correct, poses a problem for ratability, in case lives are compared that are constituted by qualitatively different experiences. If correct, a person who believes herself to be unhappy may, in fact, be happier than a person who perceives herself as happy. In other words, if we use people's own perception as a basis for judging happiness, people who have experienced few high pleasures would be judged overly optimistically. In order to meet ratability, people should not evaluate their current experiences differently purely on the basis of what they have experienced in the past. In order to meet ratability, the judgment of "very happy" for someone who has experienced few higher pleasures should correspond to the level of happiness of someone who has experienced a lot of higher pleasures and also judges herself to be "very happy". However, if QVE is true, their judgments have different consequences for happiness, and they cannot be considered equally happy. This consequence is particularly clear on a lexicographical interpretation of qualities. In order to see this, consider the following objection to ratability from a lexicographical perspective:

1) There are lexicographical differences in the quality of experiences, such that some pleasurable experiences are lexicographically more pleasurable than others.

2) Because of this lexicographical difference, the difference between higher and lower pleasures can only be evaluated by those who have experienced both. (The lexicographical version of the Quality View of Experiences (QVE I)).

3) Those who have experienced only lower pleasurable experiences are not able to evaluate the value of higher pleasurable experiences in the same way as those who have experienced both.

4) In order for self-reported SWB research to meet ratability, different subjects - or, depending on the research question, subjects over time - need to be able to evaluate the same pleasures in the same way.

5) Subjects who have experienced only the lower pleasures cannot evaluate higher pleasures in the same way as people who have experienced both.

6) SWB does not meet the ratability requirement.

On this objection, a qualitative hedonist would not accept that differences in SWB correspond to differences in happiness if there are qualitative differences in the experiences they have had. This may not be so surprising, nor may it be bothersome to an SWB researcher. The lexicographical interpretation of Mill's view may be more acceptable to people who are critical of Bentham, but may not be an attractive position for SWB researchers. After all, arguably, Mill's conception of higher and lower pleasures seems somewhat elitist: favoring some activities - typically those that people of higher classes would like - over others, on seemingly arbitrary grounds. Some SWB researchers have taken an explicit liberal stance on this issue. If a person playing simple video games says he is happy, a researcher should accept this person's judgment. There is no reason to overrule it because the researcher finds this person's judgment implausible. Martin Binder calls the liberal character of SWB an attractive normative feature of 
SWB, as it avoids the danger of paternalism (Binder, 2014) ${ }^{9}$. SWB researchers may reject the lexicographical account and ignore the lexicographical QVE objection, because its first premise (1) is rejected.

Much of the work in the lexicographical QVE objection is done by the first two premises. However, on an epistemological interpretation of Mill's view, QVE still follows, even if premises (1) and (2) are false. The beginning of the argument - the epistemological formulation of the QVE objection - would then be as follows:

$1^{*}$ ) There are differences in the quality of experiences, such that knowing how long and intense a certain pleasurable experience is, is not sufficient to evaluate how pleasurable it is.

$2^{*}$ ) Because differences in quality of experiences can only be known after they have been experienced, the difference between two qualitatively different experiences can only be evaluated by those who have experienced both (the epistemological version of the Qualitative View of Experience (QVE $\mathrm{E})$ ).

The argument would continue in the same way as the lexicographical version of the objection. On this reading, a person who spends her days playing simple computer games (a modern variant of pushpin, perhaps) would be satisfied, and may believe herself to be very happy, but could only know if her life is happier than that of a poet, or scientist, when she has, in fact, experienced the life of a scientist or poet. As a poet or scientist has probably known the experience of playing a computer game, they are in a better position to evaluate both lives. The experiences are clearly different in kind. Knowing what it is like to spend your days playing computer games probably puts you in the position to evaluate how the pleasure of playing one hour compares to playing two hours. These are differences in quantity. However, it does not put you in the position to evaluate how the pleasure of playing video games compares to finishing a beautiful poem. This view of qualitative difference in pleasure comes with fewer problematic commitments than the lexicographical view. We need not presuppose that the pleasure of finishing a beautiful poem is infinitely, or lexicographically more pleasurable than playing computer games, in order to appreciate that the pleasures are different epistemically: experiencing one pleasure tells you little about experiencing the other. QVE is thus not committed to an elitist view that certain kinds of experiences are infinitely more enjoyable, despite them not feeling as such. At the same time, it is not committed to identify every person who says she is happy as indeed being happy, because it illustrates that people may have a perception of their own happiness that is contingent on their past experiences.

To sum up: Mill provides an account of happiness in which happiness is constituted by pleasure that seems richer and more plausible than Bentham's account of happiness that is often cited in the SWB literature. However, Mill's qualitative view and his perspective on happiness evaluation (QVE) clash with a fundamental assumption in current SWB research: ratability. While one reading of Mill's view comes with its own difficulties, QVE can be formulated so that it relies only on a very commonsensical assumption that Mill stresses: some experiences can only be compared to others by those who have experienced both $\left(1^{*}\right.$ and $\left.2^{*}\right)$.

\footnotetext{
${ }_{9}^{9}$ As discussed above, within philosophical discourse there is also some debate about whether qualitative hedonism in its lexicographical interpretation is a coherent and plausible position to hold (Scarre 1997; cf Feldman 1995; Riley 1999).
} 


\section{Example: children and happiness}

The literature on SWB is expansive and various. It is not fair to make general statements regarding the neglect of the qualitative perspective in pleasurable experiences in the literature. However, one example in which the qualitative perspective seems particularly relevant, but has not been sufficiently recognized, is the study of major life changes, in particular, that of becoming a parent. Perhaps surprisingly, the literature seems in agreement that the average effect of becoming a parent on happiness is negative or close to zero. In a review of the literature, Thomas Hansen (2012) describes a common "folk view" on parenting - that it makes parents happier - but argues that the empirical evidence points in the opposite direction. People generally do not become happier from having children, if we accept the evidence from SWB research. Others are milder in their judgment of the evidence, and report that happiness may be positively affected by having children, but only "under the right conditions" (Angeles, 2009). Does this count as sound evidence that becoming a parent does not make us (or most people) happier?

On Mill's qualitative view this is problematic. Having children and not having children are qualitatively very different experiences. In fact, the two are so different, that it is hard to imagine what it is like to have children until we have them. This is exactly the point made in a recent article by Laurie Paul entitled "What you can't expect when you're expecting". In her view, having children is an epistemically transformative experience:

At least in the normal case, one has a uniquely new experience when one has one's first child. Before someone becomes a parent, she has never experienced the unique state of seeing and touching her newborn child. She has never experienced the full compendium of the extremely intense series of beliefs, emotions, physical exhaustion and emotional intensity that attends the carrying, birth, presentation, and care of her very own child, and hence she does not know what it is like to have these experiences. $(2015,8)$

Some empirical evidence supports the claim that parents do not have clearly worse experiences in general, but have different experiences. Parents may experience more stress and less pleasurable moments, also when they are with their children, but nevertheless find their activities more rewarding and find more meaning in them (White \& Dolan, 2009; Nelson et al., 2013). If Paul is correct in her judgment that having children is an experience that we cannot evaluate until we have experienced it, having children and not having children are qualitatively different experiences in the QVE sense. Consequently, on Mill's QVE, asking people about their satisfaction or their rated happiness will not be informative about which of the two experiences produces more happiness. Based on the widespread view that children do make us happier, Hansen describes the finding that parents are not happy as paradoxical. However, on Mill's perspective, the conclusion that there is a paradox does not follow ${ }^{10}$.

A possible way forward to judging the effect of parenting on happiness on Mill's account would be to give evidential priority to the opinion of parents, perhaps by asking whether they believe their experiences have improved, or if they would want their old life back. After all, the parents seem to be the "competent judges," having experienced both a childless life and a life

\footnotetext{
${ }^{10}$ QVE does not imply that the common belief about parenting and happiness is correct. It merely implies that in cases where qualitatively different lives are compared, drawing conclusions about happiness on the basis of people's self-assessment is problematic.
} 
with children. There is little scientific study that follows this, and it would deviate significantly from standard SWB methodology ${ }^{11}$.

\section{Objections to the QVE objection}

There are a number of possible objections to the claim that happiness is constituted by a combination of qualitatively different experiences whose contribution to happiness can only be judged after they have been experienced, and the problem I have argued this poses for SWB research.

A first objection may be that while ratability is often assumed in SWB studies, when more sophisticated statistical methods are used, the assumption can be relaxed without altering the results of SWB studies. This would be wrong. An influential paper about statistical methodology in SWB research is Ada Ferrer-i-Carbonell and Paul Frijters's (2004) often-cited methodological contribution that derives important conclusions from Germany's SocioEconomic Panel (GSOEP) on minimal assumptions about the structure of subjective wellbeing reports. Their statistical methodology assumes that people's satisfaction reports have an individually fixed ordinal relationship to an underlying function (in their case, welfare). In other words, it does not assume that my 7 on a life satisfaction scale is equal to yours, but it does assume that my 7 this year is higher than my 6 last year. This statistical methodology is significant in reducing the measurement requirements of happiness or satisfaction data greatly. However, it still implies that if a person's SWB score improves, so does her actual happiness, or wellbeing (see also Ferrer-i-Carbonell, 2002). On QVE, this assumption would be problematic in instances where people go through new experiences that alter their perspective. The problem goes deeper than statistical methodology. If QVE is correct, a person may evaluate happiness in a different manner now, than after having experienced something new. This goes to the heart of SWB research: a person rating her happiness lower than before may not be less happy.

A second objection may be that any view that presupposes that there are qualitatively better and worse pleasures is problematically paternalistic, even if these qualities are understood in a non-lexicographical way. This is probably a good objection against some of Mill's examples, such as his view that poetry is better than pushpin. Presupposing such hierarchies on no clear evidential ground may be considered paternalistic. Nevertheless, these views should be separated from the more abstract view that there are differences in quality between pleasures. Mill might have been wrong about the former - poetry may not be better than pushpin - but right about the latter - qualitative differences do exist. Pushpin may be of higher quality than poetry. The quality of specific experiences could even differ between different people. For me pushpin may be qualitatively better, while for others poetry may be better than pushpin. The QVE is thus not based on the view that certain specific pleasures are of a higher quality, but only that there are qualitative differences between pleasures that make the comparison between them difficult if both have not been experienced.

\section{Alternative views on happiness}

Both Mill's and Bentham's conceptions of happiness are based on the view that happiness is constituted by pleasure. A possible defense of the QVE objection can be that it does not go

\footnotetext{
${ }^{11}$ An assumption of such a methodology would be that a childless life is similar to that of the life of parents up to the moment they have children, and that having a child does not bias a person's judgment about happiness. These assumptions may be false. If that would be so, it could turn out that the question of whether parents are happier than non-parents would not be empirically answerable.
} 
through on alternative conceptions of happiness. However, what is important about the second formulation of the QVE objection is that it seems compatible with a number of different views on what constitutes happiness. Without subscribing to the view that some experiences feel infinitely more pleasurable than others, or are lexicographically more pleasurable, despite people not feeling infinitely more pleasure, it seems plausible that some experiences are harder to compare to others without having experienced both. Premises $\mathrm{A}^{*}$ and $\mathrm{B}^{*}$ in the argument are not based on a particular conception on happiness, but could apply to all conceptions of happiness that acknowledge that some form of experienced happiness can only be compared to others once they have been experienced. In order to avoid the problem QVE poses for ratability, SWB would require a conceptual view of happiness that would avoid having to commit to such qualitative differences in experiences ${ }^{12}$.

One alternative to hedonism is the view that happiness consists of an attitude towards your life: the life satisfaction view (e.g. Sumner, 1996) - a view that is popular among SWB researchers (see Haybron, 2007b). Mill seems to reject the view that attitudes are ultimately the constituents of happiness, as can be read in the distinction between happiness and contentment that he employs. Nevertheless, prima facie, it seems that an attitude view of happiness may avoid the epistemic formulation of the objection. If a person's attitude towards life is all that matters to her happiness, why would it matter whether an attitude is based on higher or lower quality experiences?

While this objection stands, it does point towards a counter-intuitive conclusion of the life satisfaction view of happiness. Consider the same person from our earlier example who spends most of her time playing computer games. This person may have a good attitude towards her life. She likes her life as it is. However, at some point, she gets a purposeful job at which she flourishes, which changes her life in many ways. In the newly-gained perspective she feels that her old attitude towards the gaming life had been inappropriate, and feels that while she has similarly positive attitudes towards her new life now as she did in the past, she is now happier. On a strict interpretation of the life satisfaction view she would have to be mistaken. After all, if her attitude towards her life is roughly the same over time, then so would be her happiness. She cannot be wrong about the attitude she had in the past. This would seem highly counterintuitive. If we would accept that attitudes can contribute differently towards happiness depending on their appropriateness, it would be conceptually possible that she is correct. However, we have now made the life satisfaction view of happiness vulnerable to QVE: the qualities of the experiences we have had can now affect the way we evaluate comparisons between different experiences, or different lives we lead. In other words, there are qualitative differences between experiences that are sufficient for QVE $\mathrm{e}$.

Another recently developed view maintains that happiness is an emotional state quality (Haybron, 2005). According to Daniel Haybron, happiness is not an experiential state, but describes our emotional state. We may be under stress, but not experience stress. In these cases, we are less happy than we would be if we were not under stress, but it is not due to a difference in pleasure. Does QVEE still pose a problem to SWB on this conception of happiness? On a first look it might not. If our emotional state were independent of our experience, we

\footnotetext{
${ }^{12}$ The epistemic version of the QVE objection to ratability could even apply to a Benthamite conception of happiness, once it is acknowledged that while pleasure may be unidimensional, pleasurable experiences are not, and that experiencing one pleasurable experience may alter your attitude towards others. On this view, pushpin and poetry may result in the same output - pleasure - but in order to know which of the two produces more, they need to be experienced.
} 
could see that the way we compare two emotional states would not depend on the qualities of the types of experiences that we have had. On the other hand, if we do evaluate our own emotional state, we are surely guided by our own experiences. Haybron himself is skeptical about our ability to know how happy we are on the grounds that we often fail to appreciate our emotional state (Haybron, 2007a). In his view, there are reasons to question ratability, independent of QVE. However, some of his reasons come close to Mill's perspective. In an example, Haybron describes a person, Glen, who has lived in the city for years under severe stress, but always had the impression he was happy. But now he moves back to the rural town where he grew up. The stress falls from his shoulders and he now realizes that his life in the city was not so happy after all. What this person experienced seems to be easily described in terms of QVEe. Glen experiences a new kind of experience - even though it is in some ways similar to his childhood, and he re-learns appreciating it: living a peaceful stressless life in the countryside. He now can fully appreciate the difference between two experiences: living a stressful life in the city, and a stressless one the countryside, and judges the countryside life to be superior in quality.

\section{QVE objection and adaptation}

The QVE is by no means the first philosophical objection against the identification of SWB with happiness. In particular, the QVE objection seems to have some similarity to the adaptation argument introduced by Amartya Sen (Sen, 1985; see Qizilbash, 2006). Both objections are based on a discrepancy between satisfaction, or people's own perception of their happiness, and their actual happiness. Mozaffar Qizilbash reads in the passages from Utilitarianism cited above the same view that Sen expresses when he discusses examples of people in deprived circumstances who nevertheless believe themselves to be happy, but clearly do not lead highquality lives. Moreover, Qizilbash believes Mill's view addresses Sen's adaptation concerns. While I believe adaptation and Mill's QVE address similar concerns, the points are different and QVE is more general. Originally, adaptation was formulated as a problem regarding people who changed their preferences due to the unavailability of a preferred option, which is a narrow and specific problem. Moreover, the term "adaptation" itself seems to suggest that it applies only after a change in desires, preferences, or ability to be happy. QVE need not involve such change. A person may have low aspirations, and be content with low pleasures, only because that person has never had the experience of higher pleasure. If anyone adapts, in Mill's examples, it is the person who learns to appreciate the higher pleasures. For Mill, examples of people who are content with little do not illustrate that they have adapted, but they illustrate that they have not fully developed their desires. The QVE objection to SWB is thus more general. Consider, for instance, the example of the gamer discussed above. In the example, the gamer is both satisfied and needs not to have adapted aspirations. However, as I argued, on Mill's account there is still a difference in happiness between her life as a gamer and her later life as a person with a successful career. In brief, the adaptation problem illustrates a problem with the satisfied that have decreased their aspirations; the QVE objection illustrates a problem with the satisfied that have never developed their aspirations.

There is another important difference in relevance to the current literature between the two problems. While the adaptation argument has been argued to be empirically falsified, as people do not, in fact, adapt to deprived circumstances (e.g. Helliwell \& Barrington-Leigh, 2010), the same could not be said for the QVE objection. 


\section{Conclusion and discussion}

In this essay I have presented and assessed a perspective found in Mill's Utilitarianism that illustrates a problem for taking self-reported SWB as sufficient evidence for happiness, in particular, in cases that involve qualitatively different experiences. While the argument is inspired by Mill's qualitative view on hedonism, it is broadly compatible with a variety of plausible views on happiness. I have argued that the problem is based on plausible foundations. Out of the currently most prominent views on happiness, only on some Benthamite and life satisfaction views of happiness can the charge be avoided. However, given the charges of superficiality that have been raised against such views, we should wonder if happiness is still a prudentially interesting concept if we accept them.

The argument presented in this essay presents a problem for the measurement of happiness by means of SWB, in particular, in contexts involving happiness comparisons on the basis of SWB between qualitatively different experiences. Nevertheless, my aim in this paper is not to criticize the SWB project as a whole. Happiness is an important feature of our lives - arguably the most important feature. It deserves to be treated in its full depth, but it also deserves to be studied. The QVE objection indicates a limit of SWB research. There are important ways in which the QVE objection can help SWB move forward. Firstly, there is a large variety of cases in which the rating of the enjoyment of experiences is not affected by the QVE objection. A straightforward example is the question of whether watching television or going to the cinema is more enjoyable to a certain group of people. The QVE objection does not seem to apply to the usage of SWB research for answering this question. In so far as watching television and going to the cinema are qualitatively different, the differences can be appreciated by those who have experienced both. The QVE objection thus helps to clarify which questions can and which questions cannot be answered by means of SWB methodology. By doing so, the QVE objection does not only indicate problems for SWB research, but also provides a stronger foundation for applications of SWB to which the QVE objection does not apply.

Another way in which the QVE may be helpful relates to the large number of puzzles and paradoxes that are characteristic of the SWB literature (e.g. Deaton \& Stone, 2013). Just like in the case of parenting discussed above, the QVE objection may help explain certain paradoxical results. Lastly, I hope the QVE will inspire new empirical ways to research happiness. Following Mill, people with a rich experiential basis could be an important source of knowledge about happiness. As Haybron's example of Glen illustrates, studying how people experience transitions between qualitatively different lives may be an important source of information about how happy different lives are. It may be that qualitatively different experiences should be addressed by means of different research methodologies. Happiness is a complex concept, and studying it will never be easy. However, awareness of the limitations of existing methods will ultimately bring the field of study forward.

\section{Acknowledgments}

I would like to thank Constanze Binder, Philippe Verreault-Julien and two anonymous referees for helpful comments. I presented a version of the article in the EIPE PhD seminar in Rotterdam, 21 September 2015. I would like to thank the audience for helpful feedback.

\section{Author}

Willem van der Deijl

Erasmus University Rotterdam

vanderdeijl@ese.eur.nl 


\section{Publishing Timeline}

Received 17 August 2015

Accepted 18 December 2015

Published 14 May 2016

\section{References}

Angeles, L. (2009). Children and life satisfaction. Journal of Happiness Studies, 11(4), 523-538. http://dx.doi.org/10.1007/s10902-009-9168-z

Angner, E. (2010). Subjective well-being. The Journal of Socio-Economics, 39(3), 361-368. http://dx.doi.org/10.1016/j.socec.2009.12.001

Anger, E. (2013). Is it possible to measure happiness? European Journal for Philosophy of Science, 3(2), 221240. http://dx.doi.org/10.1007/s13194-013-0065-2

Binder, M. (2014). Subjective well-being capabilities: Bridging the gap between the capability approach and subjective well-being research. Journal of Happiness Studies, 15(5), 1197-1217. http://dx.doi.org/10.1007/s10902-013-9471-6

Booher, T. (2007). J. S. Mill's test for higher pleasure. Studies in the History of Ethics, 1-17. http://www.historyofethics.org/122007/122007Booher.shtml

Crespo, R. F., \& Mesurado, B. (2014). Happiness economics, eudaimonia and positive psychology: From happiness economics to flourishing economics. Journal of Happiness Studies, 16(4), 931-946. http://dx.doi.org/10.1007/s10902-014-9541-4

Crisp, R. (2006). Hedonism reconsidered. Philosophy and Phenomenological Research, 73(3), 619-645. http://dx.doi.org/10.1111/j.1933-1592.2006.tb00551.x

Deaton, A., \& Stone, A. A. (2013). Two happiness puzzles. The American Economic Review, 103(3), 591-597. http://dx.doi.org/10.1257/aer.103.3.591

Dolan, P., \& Metcalfe, R. (2012). Measuring subjective wellbeing: Recommendations on measures for use by national governments. Journal of Social Policy, 41(2), 409-427. http://dx.doi.org/10.1017/S0047279411000833

Feldman, F. (1995). Mill, Moore, and the consistency of qualified hedonism. Midwest Studies in Philosophy, 20(1), 318-331. http://dx.doi.org/10.1111/j.1475-4975.1995.tb00319.x

Feldman, F. (2010). What is this thing called happiness? New York: Oxford University Press. http://dx.doi.org/10.1093/acprof:oso/9780199571178.001.0001

Ferrer-i-Carbonell, A. (2002). Subjective questions to measure welfare and well-being. (Tinbergen Institute Discussion Paper). Unpublished manuscript

Fleurbaey, M., \& Blanchet, D. (2013). Beyond GDP: Measuring welfare and assessing sustainability. New York: Oxford University Press. http://dx.doi.org/10.1093/acprof:oso/9780199767199.001.0001

Hansen, T. (2012). Parenthood and happiness: A review of folk theories versus empirical evidence. Social Indicators Research, 108(1), 29-64. http://dx.doi.org/10.1007/s11205-011-9865-y

Haybron, D. M. (2005). On being happy or unhappy. Philosophy and Phenomenological Research, 71(2), 287317. http://dx.doi.org/10.1111/j.1933-1592.2005.tb00450.x

Haybron, D. M. (2007a). Do we know how happy we are? On some limits of affective introspection and recall. Nous, 41(3), 394-428. http://dx.doi.org/10.1111/j.1468-0068.2007.00653.x

Haybron, D. M. (2007b). Life satisfaction, ethical reflection, and the science of happiness. Journal of Happiness Studies, 8(1), 99-138. http://dx.doi.org/10.1007/s10902-006-9006-5

Helliwell, J. F., \& Barrington-Leigh, C. P. (2010). Viewpoint: Measuring and understanding subjective well-being. The Canadian Journal of Economics / Revue Canadienne d'Economique, 43(3), 729-753. http://dx.doi.org/10.1111/j.1540-5982.2010.01592.x

Kahneman, D., \& Krueger, A. B. (2006). Developments in the measurement of subjective well-being. The Journal of Economic Perspectives, 20(1), 3-24. http://dx.doi.org/10.1257/089533006776526030

Kahneman, D., Krueger, A. B., Schkade, D., Schwarz N., \& Stone, A. (2004). Toward national well-being accounts. The American Economic Review, 94(2), 429-434. http://dx.doi.org/10.1257/0002828041301713 
Kahneman, D., Wakker, P. P., \& Sarin, R. (1997). Back to Bentham? Explorations of experienced utility. The Quarterly Journal of Economics, 112(2), 375-405. http://dx.doi.org/10.1162/003355397555235

Kawall, J. (1999). The experience machine and mental state theories of well-being. The Journal of Value Inquiry, 33(3), 381-387. http://dx.doi.org/10.1023/A:1004557501837

Kesebir, P, \& Diener E. (2008). In pursuit of happiness: Empirical answers to philosophical questions. Perspectives on Psychological Science, 3(2), 117-125. http://dx.doi.org/10.1111/j.1745-6916.2008.00069.x

MacKerron, G. (2012). Happiness economics from 35000 feet. Journal of Economic Surveys, 26(4), 705-735. http://dx.doi.org/10.1111/j.1467-6419.2010.00672.x

Mill, J. S. (1998). Utilitarianism. In R. Crisp (Ed.), Oxford Philosophical Texts. London: Oxford University Press.

Nelson, S., Kostadin Kushlev, K., English, T., Dunn, E. W., \& Lyubomirsky, S. (2013). In defense of parenthood: Children are associated with more joy than misery. Psychological Science, 24(1), 3-10. http://dx.doi.org/10.1177/0956797612447798

Nozick, R. (1974). Anarchy, state, and utopia. New York: Basic Books.

Nussbaum, M. C. (2004). Mill between Aristotle \& Bentham. Daedalus, 133(2), 60-68. http://dx.doi.org/10.1162/001152604323049406

Nussbaum, M. C. (2008). Who is the happy warrior? Philosophy poses questions to psychology. The Journal of Legal Studies, 37(S2), S81-113. http://dx.doi.org/10.1086/587438

O'Neill, J. (2006). Feature Review. New Political Economy, 11(3), 447-450. http://dx.doi.org/10.1080/13563460600841173

Paul, L. A. (2015). What you can't expect when you're expecting. Res Philosophica, 92(2), 1-23. http://dx.doi.org/10.11612/resphil.2015.92.2.1

Qizilbash, M. (2006). Capability, happiness and adaptation in Sen and J. S. Mill. Utilitas, 18(01), 20-32.

Raibley, J. R. (2012). Happiness is not well-being. Journal of Happiness Studies, 13(6), 1105-1129. http://dx.doi.org/10.1007/s10902-011-9309-z

Riley, J. (1999). Is qualitative hedonism incoherent? Utilitas, 11(3), 347-358.

Riley, J. (2003). Interpreting Mill's qualitative hedonism. The Philosophical Quarterly, 53(212), 410-418. http://dx.doi.org/10.1111/1467-9213.00321

Saunders, B. (2011.) Reinterpreting the qualitative hedonism advanced by J.S. Mill. The Journal of Value Inquiry, 45(2), 187-201. http://dx.doi.org/10.1007/s10790-011-9274-0

Scarre, G. (1997). Donner and Riley on qualitative hedonism. Utilitas, 9(3), 351-360. http://dx.doi.org/10.1017/S0953820800005422

Schmidt-Petri, C. (2003). Mill on quality and quantity. The Philosophical Quarterly, 53(210), 102-104. http://dx.doi.org/10.1111/1467-9213.00301

Schmidt-Petri, C. (2006). On an interpretation of Mill's qualitative utilitarianism. Prolegomena, 5(2), 165177.

Sen, A. K. (1985). Commodities and Capabilities. New Delhi: Oxford University Press.

Sen, A. K. (2006). Reason, freedom and well-being. Utilitas, 18(1), 80-96. http://dx.doi.org/10.1017/S0953820805001846

Sen, A. K. (2008). The economics of happiness and capability. In L. Bruni, F. Comim \& M. Pugno (Eds.), Capability and happiness. New York: Oxford University Press.

Silverstein, M. (2000). In defense of happiness: A response to the experience machine. Social Theory and Practice, 26(2), 279-300. http://dx.doi.org/10.5840/soctheorpract200026225

Stewart, F. (2014). Against happiness: A critical appraisal of the use of measures of happiness for evaluating progress in development. Journal of Human Development and Capabilities, 15(4), 293-307. http://dx.doi.org/10.1080/19452829.2014.903234

Sumner, L. W. (1996). Welfare, happiness, and ethics. Oxford: Oxford University Press.

Tännsjö, T. (2007). Narrow Hedonism. Journal of Happiness Studies, 8(1), 79-98. http://dx.doi.org/10.1007/s10902-006-9005-6

Veenhoven, R. (2010). Greater happiness for a greater number: Is that possible and desirable? Journal of Happiness Studies, 11(5), 605-629. http://dx.doi.org/10.1007/s10902-010-9204-z 
Weijers, D. (2011). The experience machine objection to hedonism. In M. Bruce \& S. Barbone (Eds.), Just the arguments: 100 of the most important arguments in western philosophy. Oxford: Wiley-Blackwell, pp. 229-231. http://dx.doi.org/10.1002/9781444344431.ch58

Weijers, D., \& Schouten, V. (2013). An assessment of recent responses to the experience machine objection to hedonism. Journal of Value Inquiry, 2(9), 461-482. http://dx.doi.org/10.1007/s10790-013$\underline{9395-8}$

White, M. P., \& Dolan, P. (2009). Accounting for the richness of daily activities. Psychological Science, 20(8), 1000-1008. http://dx.doi.org/10.1111/j.1467-9280.2009.02392.x 